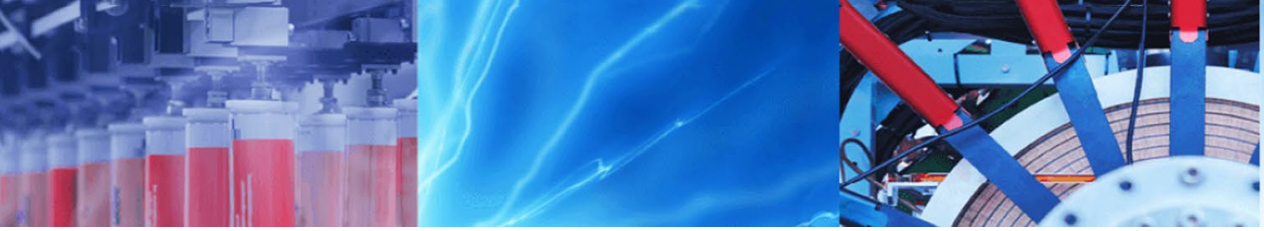

Research Article

\title{
Experimental investigation on laponite as ultra-high-temperature viscosifier of water-based drilling fluids
}

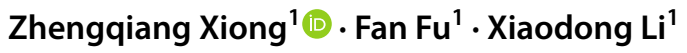

(c) Springer Nature Switzerland AG 2019

\begin{abstract}
Aimed at the problem of poor anti-temperature capability of polymer viscosifier, which cannot meet the needs of ultrahigh-temperature water-based drilling fluid, laponite has been studied as an ultra-high-temperature viscosifier. The property of thickening, temperature resistance and salt tolerance of laponite are evaluated. In addition, the viscosifying mechanism of laponite under high temperature has also been analyzed. Experimental results show that laponite has excellent viscosifying ability and thermal stability, and it is able to function at temperature of up to $260^{\circ} \mathrm{C}$. Moreover, the viscosifying effect at high temperature is superior to high-temperature viscosifiers used worldwide. In practice, the reduced rate of apparent viscosity value of bentonite dispersion formulated with $1 \mathrm{wt} \%$ laponite is $0 \%$ after aging at $260^{\circ} \mathrm{C}$ for $16 \mathrm{~h}$, while that of bentonite dispersion with $1 \mathrm{wt} \% \mathrm{HE} 300$ is $94.7 \%$. Research results indicate that laponite is compatible well with other commonly used additives and has promising application as ultra-high-temperature viscosifier in formulating ultra-high-temperature water-based drilling fluid.
\end{abstract}

Keywords Laponite - Ultra-high-temperature viscosifier · High-temperature tolerance $\cdot$ Water-based drilling fluid

\section{Introduction}

Bottom hole temperature can exceed $240{ }^{\circ} \mathrm{C}$ during the implementation of the exploration and development in deep hydrocarbon and hot dry rock resources. This makes the drilling fluid exposed to high-temperature environment for long periods, creating new challenges for temperature resistance of drilling fluids. Various components of drilling fluid will change under ultra-high temperature. Especially, viscosifier is an important ingredient of waterbased drilling fluids to viscosify the fluid and suspend drilling cuttings. However, polymer viscosifiers do not maintain their properties in high-temperature water-based drilling fluids due to their thermal degradation. Previously, a variety of polymer viscosifiers with higher thermal stability were synthesized to solve the drawback. Yan et al. [1, 2] synthesized a novel amphiphilic comb-like terpolymer, which improved the rheological and filtration properties of water-based drilling fluids under a high temperature of $150^{\circ} \mathrm{C}$. Xie et al. [3] synthesized a novel copolymer viscosifier, which had thickening ability and thermal resistance after aging tests at $230{ }^{\circ} \mathrm{C}$ for $16 \mathrm{~h}$. Boul et al. [4] developed a supramolecular viscosifier, which displayed rheological recovery after aging at high temperature and retained its viscosity at temperatures up to $162.7^{\circ} \mathrm{C}$. However, to our knowledge, currently there is no polymer viscosifier available that can tolerate the temperature up to $240{ }^{\circ} \mathrm{C}$. Therefore, it is necessary to look for other new materials to maintain the viscosifying ability under ultra-high temperature.

Laponite is a synthetic material with structure and composition similar to natural hectorite. It is a 2:1 swelling phyllosilicate mineral with an octahedral $\mathrm{MgO}$ sheet sandwiched in between two tetrahedral silica sheets. Laponite particle has a disk-shaped structure with the diameter of $25 \mathrm{~nm}$ and thickness of $1 \mathrm{~nm}$ [5-7] (see Fig. 1). Because of the nanoscale-sized layers and unique crystal structure, laponite easily hydrates and forms a gel structure in water and has been used as a rheological modifier or thixotropic agent in

Zhengqiang Xiong, xiongzq1012@126.com | 'Beijing Institute of Exploration Engineering, Beijing 100083, China.

SN Applied Sciences (2019) 1:1374 | https://doi.org/10.1007/s42452-019-1434-z

Received: 23 July 2019 / Accepted: 9 October 2019 / Published online: 11 October 2019

SN Applied Sciences 


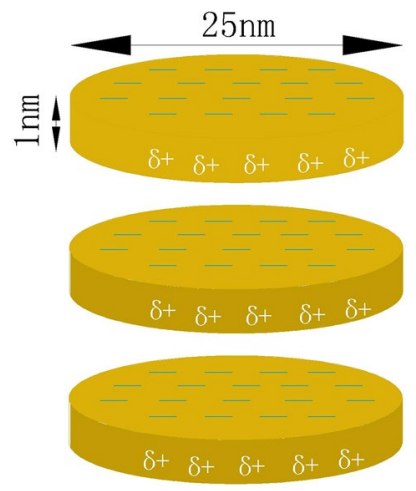

Fig. 1 Schematic diagram of laponite structure

coatings, medicine and household/personal care. At present, laponite has been mainly investigated in preparation $[8,9]$, laponite nanocomposite [10], laponite organic modification [11], stabilizers of Pickering emulsions [12] and colloid rheology of laponite dispersions [7, 13-15]. In the drilling fluid area, applications of laponite in water-based drilling fluids were seldom reported. Rare examples include usage of laponite as a multi-functional additive [16], viscosifier [17], shale inhibitor [18] and mud-making material [19]. Qin et al. [17] synthesized laponite in laboratory using microwave irradiation method and tested the viscosifying property of laponite in water-based drilling fluid at elevated temperatures. However, the maximum test temperature of laponite is $220^{\circ} \mathrm{C}$, and viscosifying mechanism of laponite needs to be studied more deeply. In a previous study [19], we have thoroughly evaluated the dispersive property of laponite under different conditions and have noted that laponite has excellent dispersibility at high temperature and is suitable for use as a mud-making material to prepare ultra-hightemperature water-based drilling fluids.

Herein, we evaluated the viscosifying capability of laponite used as ultra-high-temperature viscosifier in ultra-high-temperature water-based drilling fluids and comprehensively analyzed its viscosifying mechanism. The viscosifying performance of laponite was tested in terms of laponite concentration, temperature and thermal aging time. For comparison, two high-temperature resistant viscosifiers were used as control group. Finally, the performance of ultra-high-temperature water-based drilling fluid containing different viscosifiers was discussed.

\section{Materials and methods}

\subsection{Materials}

Laponite was provided by Nanjing Baiyike New Material Technology Co., Ltd, its chemical composition (wt\%: $\mathrm{SiO}_{2}$

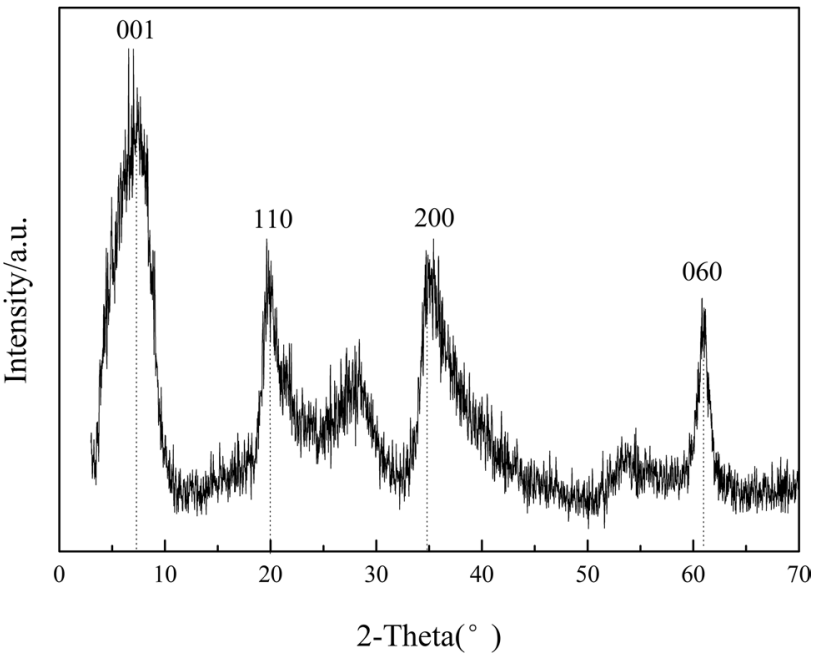

Fig. 2 X-ray powder diffraction pattern of laponite

47.73, $\mathrm{MgO} 25.36, \mathrm{Na}_{2} \mathrm{O} 2.42$ and $\mathrm{Li}_{2} \mathrm{O}$ 1.36) was determined by inductively coupled plasma atomic emission spectroscopy (PerkinElmer Optima 8300 Series), and X-ray powder diffraction (XRD) analysis was done by SmartLab type X-ray diffractometer (Rigaku Corp., Japan), as shown in Fig. 2. Sodium bentonite was purchased from Xiazijie Bentonite Co., Ltd; its chemical composition (wt\%: $\mathrm{SiO}_{2}$ 64.06, $\mathrm{Al}_{2} \mathrm{O}_{3}$ 16.97, $\mathrm{Fe}_{2} \mathrm{O}_{3}$ 5.66, $\mathrm{MgO} 1.99, \mathrm{CaO} 0.77, \mathrm{~K}_{2} \mathrm{O}$ 1.90, $\mathrm{Na}_{2} \mathrm{O} 1.42$ and $\mathrm{TiO}_{2}$ 0.91) was measured by X-ray fluorescence spectrometer (Thermo ARL ADVANTXP+). The polymer viscosifier (HE 300) and polymer viscosifying and filtrate reducing agent (DRISCAL D) were supplied by Chevron Phillips Chemical company.

\subsection{Characterization of laponite}

The thermal stability of samples was measured using thermogravimetric analysis (TGA) on an STA 449 F3 type synchronous thermal analyzer (NETZSCH Group, DE), which worked at the scanning rate of $10^{\circ} \mathrm{C} / \mathrm{min}$ within the temperature of $25-600{ }^{\circ} \mathrm{C}$.

\subsection{Measurements of zeta potential and particle size}

Zeta potentials of different dispersions were measured by the Zetasizer Nano ZS90 analyzer (Malvern Instruments $\mathrm{Ltd}, \mathrm{UK}$ ) at room temperature. Prior to the measurements, dispersions were diluted 10 times with distilled water. Each sample was then analyzed three times in duplicate, and the average value of zeta potential was used for analysis.

Particle size distributions of different dispersions were measured by a LA-950V2 Laser Particle Size Analyzer (HORIBA, Japan) at room temperature. 


\subsection{Measurements of rheological properties and filtrate volume}

To evaluate the temperature resistance, drilling fluids or bentonite dispersions were transferred into sealed aging cell and rolled for $16 \mathrm{~h}$ at appointed temperature using XGRL-4A type hot rolling furnace (Qingdao Haitongda Special Instruments CO., LTD., China). Then, the fluids were cooled to room temperature, and fluids performance tests were conducted.

The rheological properties of drilling fluids were measured before and after hot rolling aging tests using a HTD13145 type rotating viscometer (Qingdao Haitongda Special Instruments CO., LTD., China). The apparent viscosity (AV), plastic viscosity (PV) and yield point (YP) were calculated according to American Petroleum Institute (API) standard [20].

The API filtrate volume (FL) and the high-temperature and high-pressure filtrate volume (HTHP filtrate) of the drilling fluids were determined with a SD6A type medium-pressure filtration apparatus (Qingdao Haitongda Special Instruments CO., LTD., China) and a GGS71-B type high-temperature and high-pressure filtration apparatus (Qingdao Haitongda Special Instruments CO., LTD., China), respectively. The FL and HTHP filtrate were determined at $25^{\circ} \mathrm{C}, 0.69 \mathrm{MPa}$, and $220^{\circ} \mathrm{C}, 3.45 \mathrm{MPa}$, respectively.

\section{Results and discussion}

\subsection{Viscosifying property of laponite}

Different factors influencing viscosifying property of laponite in water-based drilling fluids were studied, including dosage of laponite, temperature, thermal aging time and salt.

\subsubsection{Effect of dosage of laponite on viscosifying property of laponite}

Laponite was added to $4 \mathrm{wt} \%$ bentonite dispersion at different concentrations $(0.5,1.0,1.5$, and $2.0 \mathrm{wt} \%)$. Note that $0.5 \mathrm{wt} \%$ meant $0.5 \mathrm{~g}$ laponite was added to $100 \mathrm{~g}$ bentonite dispersion to form $0.5 \mathrm{~g} / 100 \mathrm{~g}$. Bentonite dispersion formulated with different concentrations of laponite was subjected to aging for $16 \mathrm{~h}$ at $220^{\circ} \mathrm{C}$. The effect of dosage of laponite on viscosifying property of laponite was studied, and the results are displayed in Table 1. With the concentration of laponite increasing, apparent viscosity, ratio of yield point to plastic viscosity (known as YP/PV ratio) and gel strength value of bentonite dispersion gradually increase; however, filtration loss (FL) shows a decreasing tendency.
Table 1 Performance of bentonite dispersion with different dosages of laponite

\begin{tabular}{lllll}
\hline $\begin{array}{l}\text { Laponite } \\
\text { (wt\%) }\end{array}$ & AV (mPa s) & $\begin{array}{l}\text { YP/PV ratio } \\
(\mathrm{Pa} / \mathrm{mPa})\end{array}$ & $\begin{array}{l}\text { Gel strength } \\
(\mathrm{Pa} / \mathrm{Pa})\end{array}$ & $\mathrm{FL}(\mathrm{mL})$ \\
\hline 0 & 8 & 0.32 & $0.5 / 4.5$ & 23 \\
0.5 & 10 & 0.32 & $0.5 / 4$ & 24 \\
1 & 16.5 & 0.36 & $1 / 9$ & 24 \\
1.5 & 23 & 0.42 & $2.5 / 14$ & 20 \\
2 & 41.5 & 1.03 & $8 / 28$ & 19 \\
\hline
\end{tabular}

\subsubsection{Effect of temperature on viscosifying property of laponite}

Theoretically, the temperature in well increases when the depth of borehole increases. Therefore, the effect of temperature on viscosifying performance of laponite was evaluated. $4 \mathrm{wt} \%$ bentonite dispersion formulated with $1 \mathrm{wt} \%$ laponite was subjected to aging for $16 \mathrm{~h}$ at different temperatures varying from 80 to $260^{\circ} \mathrm{C}$. It can be seen that $A V$ value of bentonite dispersions containing laponite first increases and then decreases and finally increases slowly with the temperature increasing (Fig. 3a). For instance, as the aging temperature increases from 220 to $260^{\circ} \mathrm{C}$, the $A V$ values of bentonite dispersion are kept constant at $16.5 \mathrm{mPa}$ s. As observed in Fig. 3b, as the aging temperature increases, YP/PV ratio value of bentonite dispersions first increases slowly and then decreases gradually. These data demonstrate that laponite has excellent high-temperature viscosifying property, and its temperature resistance is up to $260^{\circ} \mathrm{C}$.

\subsubsection{Effect of thermal aging time on viscosifying property of laponite}

$4 \mathrm{wt} \%$ bentonite dispersion with the addition of $1 \mathrm{wt} \%$ laponite was aged for different hours at $220^{\circ} \mathrm{C}$. The effect of thermal aging time on viscosifying property of laponite was studied, and the results are displayed in Table 2. As the thermal aging time at $220^{\circ} \mathrm{C}$ extends from 16 to $72 \mathrm{~h}, \mathrm{AV}$ and YP/PV ratio value of bentonite dispersion rise during $24 \mathrm{~h}$, but drop gradually with increasing aging time, while gel strength and $F L$ value of bentonite dispersion show a decreasing tendency. It is further shown that laponite has excellent high-temperature viscosifying property.

\subsubsection{Effect of salt on viscosifying property of laponite}

Different amounts of $\mathrm{NaCl}(5,10,15$ and $20 \mathrm{~g})$ were added to $4 \mathrm{wt} \%$ bentonite dispersion with $1 \mathrm{wt} \%$ laponite $(100 \mathrm{~g})$. The influence of salt on viscosifying property of laponite was measured before and after aging at $200^{\circ} \mathrm{C}$ for $16 \mathrm{~h}$, 

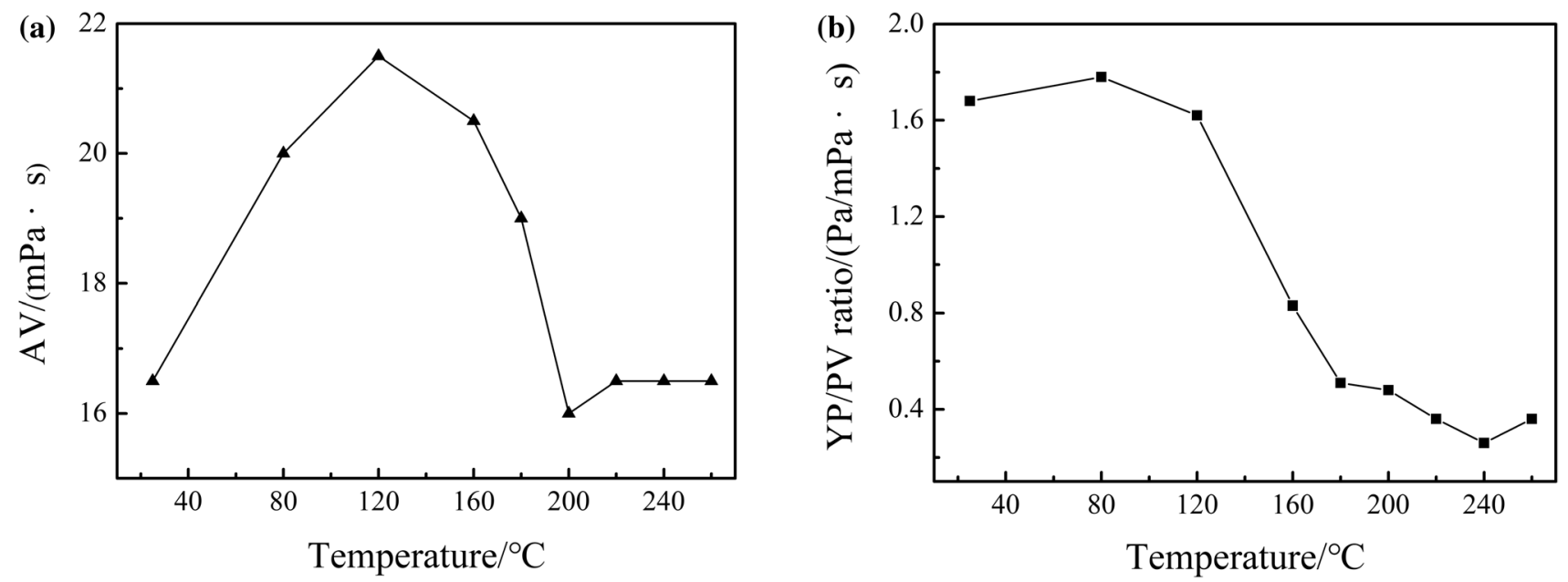

Fig. 3 Effect of temperature on the performance of bentonite dispersion containing laponite: $\mathbf{a} A V ; \mathbf{b}$ YP/PV ratio

Table 2 Performance of bentonite dispersion containing laponite under different thermal aging times

\begin{tabular}{lllll}
\hline $\begin{array}{l}\text { Thermal } \\
\text { aging time } \\
\text { (h) }\end{array}$ & AV (mPa s) & $\begin{array}{l}\text { YP/PV ratio } \\
(\mathrm{Pa} / \mathrm{mPa} \text { s) }\end{array}$ & $\begin{array}{l}\text { Gel strength }(\mathrm{Pa} / \\
\mathrm{Pa})\end{array}$ & $\mathrm{FL}(\mathrm{mL})$ \\
\hline 16 & 16.5 & 0.27 & $1 / 9$ & 24 \\
24 & 19 & 0.36 & $0.5 / 14$ & 18 \\
36 & 17 & 0.21 & $0.5 / 10.5$ & 19 \\
48 & 16.5 & 0.18 & $0.25 / 7$ & 20 \\
72 & 13 & 0.18 & $0.25 / 3$ & 19 \\
\hline
\end{tabular}

and the results are depicted in Fig. 4. As the $\mathrm{NaCl}$ concentration increases, AV value of dispersion first decreases and then increases and finally decreases before aging or after aging at $200{ }^{\circ} \mathrm{C}$, and YP value of dispersion first increases and then decreases. Furthermore, after adding $\mathrm{NaCl}$, the YP value of dispersion is almost higher than dispersion without sodium chloride. Yield point represents the strength of the ability to form the "house of cards" structure. Individual laponite dispersion or sodium bentonite dispersion showed a poor salt resistance in a previous study [19], while bentonite dispersion with laponite presents good salt tolerance. The reason is possible that the stable "house of cards" structure is formed due to the influence of disk-shaped laponite nanoparticles on adsorbing onto montmorillonite particles surface in the presence of sodium chloride. Of course, specific reasons of interaction between laponite particles and montmorillonite particles need to be further studied under high $\mathrm{NaCl}$ concentration.
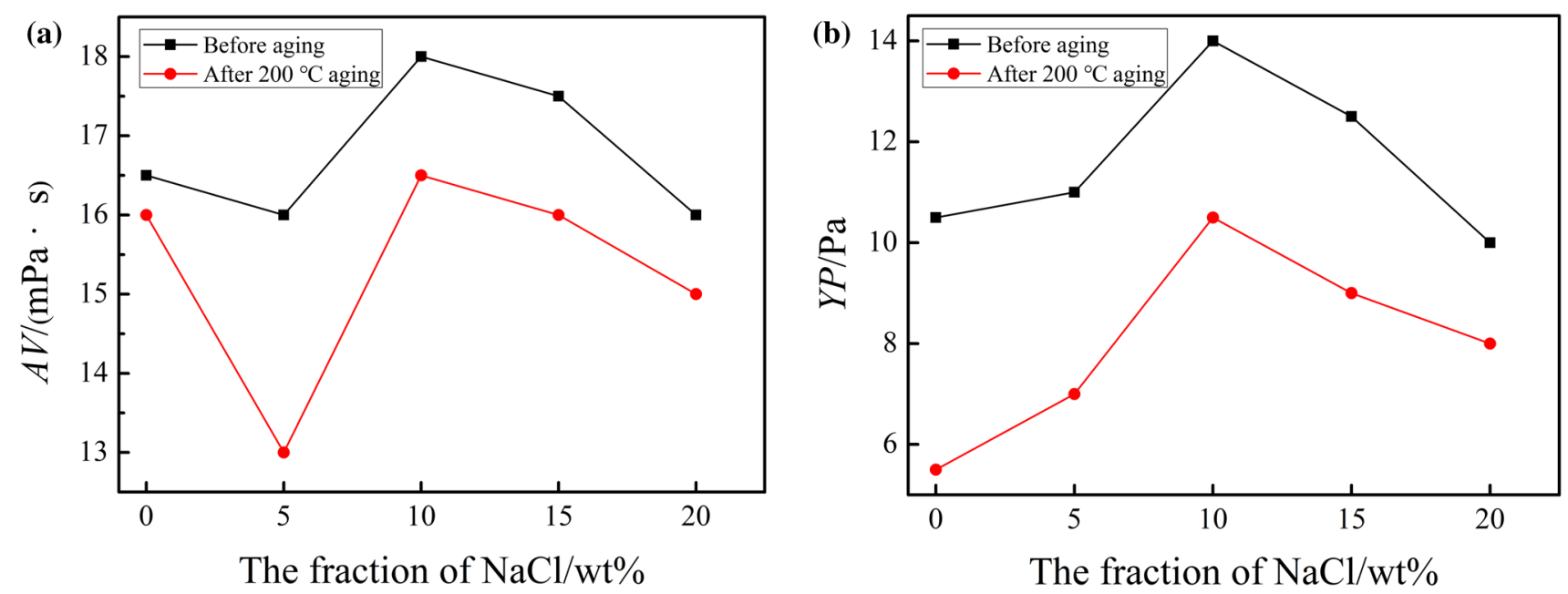

Fig. 4 Effect of salt on the performance of bentonite dispersion containing laponite: a AV; $\mathbf{b}$ YP 


\subsubsection{Viscosifying mechanism of laponite}

To clarify the reason behind the high-temperature viscosifying property of laponite, the performance of bentonite dispersion formulated with $1 \mathrm{wt} \%$ laponite was investigated in terms of apparent viscosity, yield point, average particle diameter and zeta potential (Fig. 5). As shown in Fig. 5, the AV, YP and average particle diameter value of bentonite dispersion containing laponite are all greater than bentonite dispersion at the same temperature, but lower than bentonite dispersion in zeta potential. As aging temperature increases, the AV value of bentonite dispersion first increases and then kept almost constant (Fig. 5a), while YP value has minor change (see Fig. 5b). The average particle diameter of both the bentonite dispersion and bentonite dispersion with laponite displays the declining tendency at the beginning and increasing slowly in late with the increase in temperature (Fig. 5c). As observed in
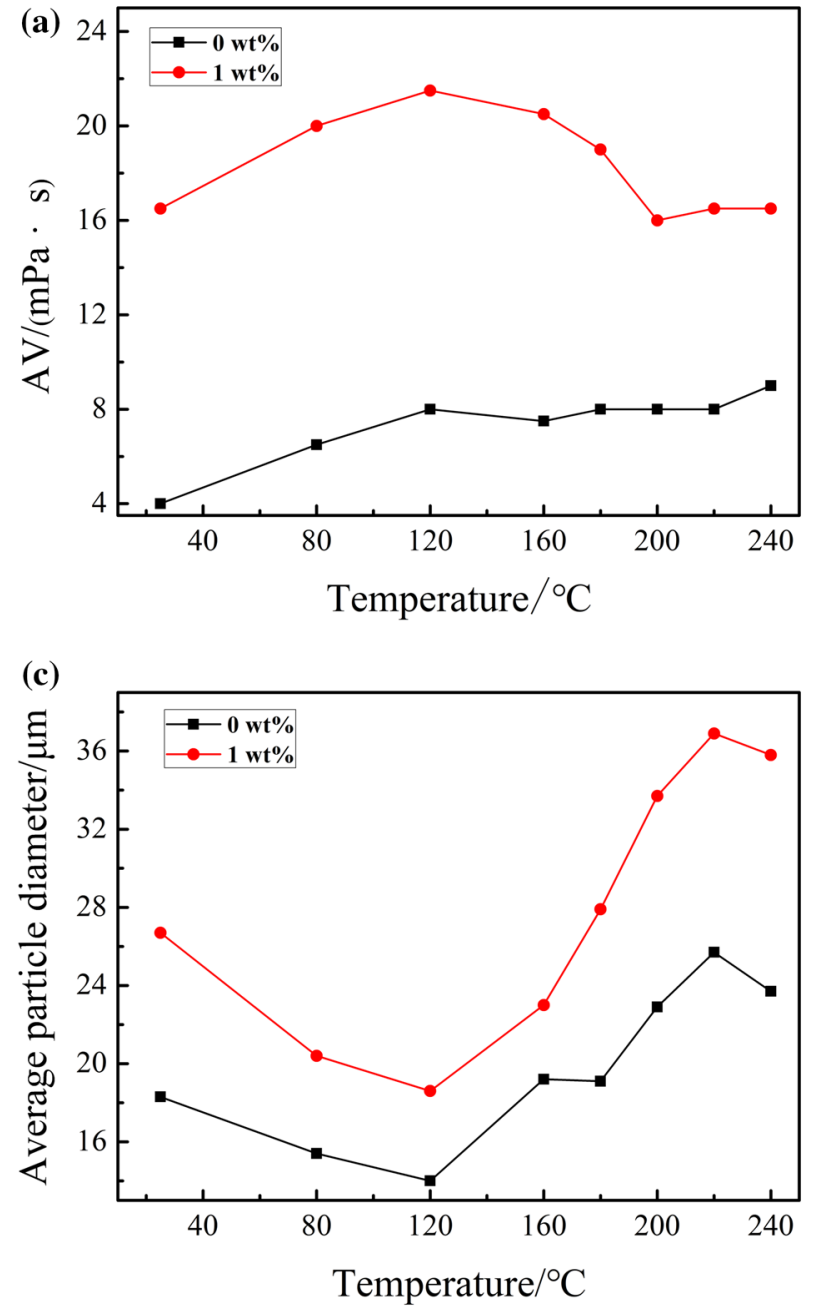

Fig. $5 d$, as aging temperature increased, the zeta potential value of bentonite dispersion first decreases and then increases slowly, but the zeta potential value of bentonite dispersion with laponite shows the declining tendency at the beginning and increasing slowly in late.

Interlayer cations of laponite are mainly composed of sodium and lithium counterions [19]. By reason of small radius and high hydration energy of $\mathrm{Na}^{+}$and $\mathrm{Li}^{+}$, water molecules can be easily adsorbed on the surfaces of laponite particles. The electrostatic attractions of particle lamellae can be overcome by repulsive forces, causing the swelling and exfoliating of laponite sheets (see Fig. 1). Therefore, when laponite is added to the bentonite dispersion, the primary particles of laponite are absorbed on the surface of montmorillonite particles by electrostatic attractions, and electrical double layer thickness of montmorillonite particle increases, which results in the increase in the average particle diameter
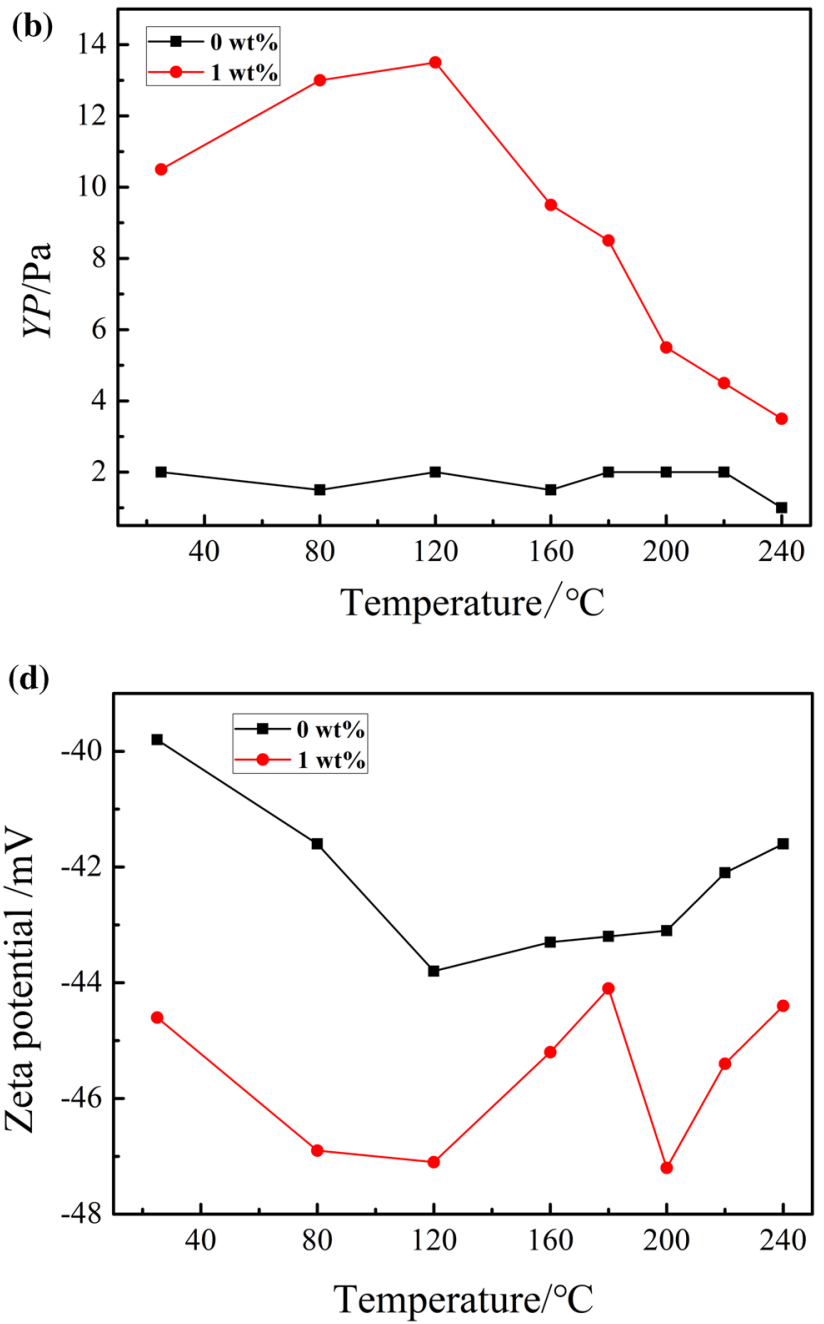

Fig. 5 Effect of viscosifier laponite on the performance of bentonite dispersion at different temperatures: a AV; b YP; c average particle diameter; $\mathbf{d}$ zeta potential 
and in a decrease in zeta potential. Moreover, through adsorption of laponite on the surface of montmorillonite particles, the spatial network structure of montmorillonite particles and the internal friction force of dispersion are further enhanced, which leads to an increase in AV and YP of bentonite dispersion containing laponite.

With the increase in temperature, the properties of bentonite dispersion containing laponite have changed as follows:

1. In the temperature range of $25-120^{\circ} \mathrm{C}$, thermal motion of water molecules and surface activity of clay particles increase when temperature rises, which promotes the further hydration and dispersion of clay particles, so the average particle diameter and zeta potential of dispersions decrease. In addition, the stronger spatial network structure of montmorillonite particles is formed by adsorption of laponite on the surface of montmorillonite particles, and the internal friction force of dispersion also increases, which leads to an increase in $\mathrm{AV}$ and $\mathrm{YP}$ of bentonite dispersion containing laponite.

2. In the temperature range of $120-240^{\circ} \mathrm{C}$, as the temperature further increases, thermal motion of water molecules increases; however, the surface activity of laponite and montmorillonite particles decreases. Consequently, hydration shells of clay particles thin and clay particles aggregates, which causes the increase in average particle diameter and zeta potential of bentonite dispersion containing laponite. Then, the aggregate of clay particles weakens the strength of the spatial network structure and brings about the decrease in $\mathrm{AV}$ and $\mathrm{YP}$ of bentonite dispersion containing laponite.

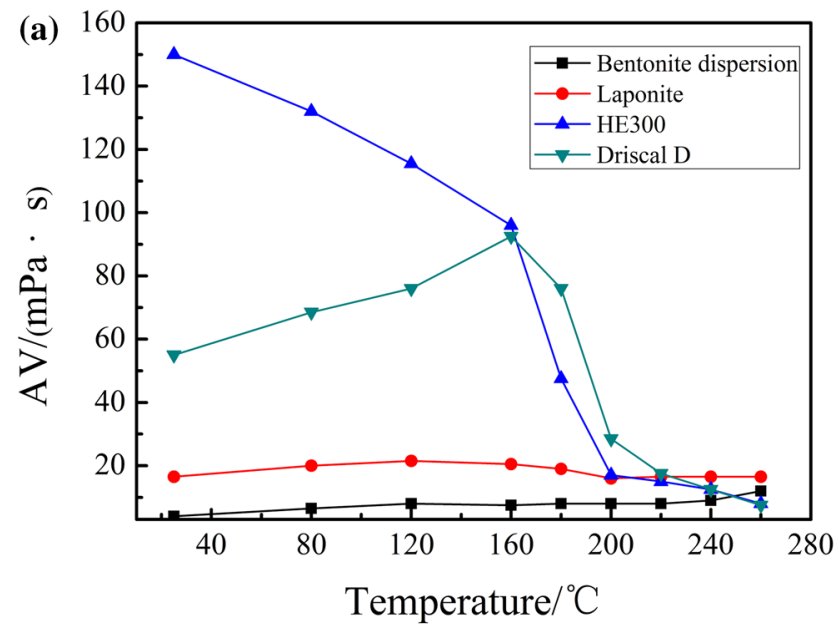

\subsection{Performance comparison between laponite and high-temperature viscosifier}

A comparison of viscosification property between laponite, viscosifier HE300 and DRISCAL D which are representative of high-temperature polymer viscosifiers worldwide was made, and the results are depicted in Fig. 6.

It can be shown that the AV and YP/PV ratio value of bentonite dispersions with viscosifier $\mathrm{HE} 300$ fall as temperature continues to rise (Fig. 6). In Fig. 6a, the AV of bentonite dispersion with viscosifier DRISCAL $D$ first increases and then reduces when temperature increases, but its YP/PV ratio decreases gradually (Fig. $6 \mathrm{~b}$ ). On the other hand, the viscosification property of two kinds of polymer viscosifiers has an advantage over laponite before temperature of $160^{\circ} \mathrm{C}$. However, when the temperature is above $180^{\circ} \mathrm{C}$, the YP/PV ratio value of bentonite dispersion with laponite is greater than HE300 and DRISCAL D. For instance, after aging for $16 \mathrm{~h}$ at $260^{\circ} \mathrm{C}$, the YP/PV ratio of bentonite dispersion with laponite, HE300 and DRISCAL D is $0.36,0.14$ and 0.24 , respectively. Moreover, the AV value of bentonite dispersion with laponite is also greater than HE300 and DRISCAL D when the temperature exceeds $240^{\circ} \mathrm{C}$. Specifically, after aging for $16 \mathrm{~h}$ at $260^{\circ} \mathrm{C}$, the $\mathrm{AV}$ value of bentonite dispersion containing laponite, HE300 and DRISCAL D is $16.5 \mathrm{mPa} \mathrm{s}, 8 \mathrm{mPa}$ s and $7.5 \mathrm{mPa}$, respectively. These results confirm that laponite is superior to polymer viscosifiers in terms of cutting carrying capacity of drilling fluids at ultra-high temperature, and it can be used as an ultrahigh-temperature viscosifier in water-based drilling fluids.

In order to further analyze the temperature resistance of different viscosifiers, the thermogravimetric analysis was carried out, and the results are shown in Fig. 7. The thermal decomposition process of HE300 and DRISCAL D can be divided into three stages. Both HE300 and DRISCAL

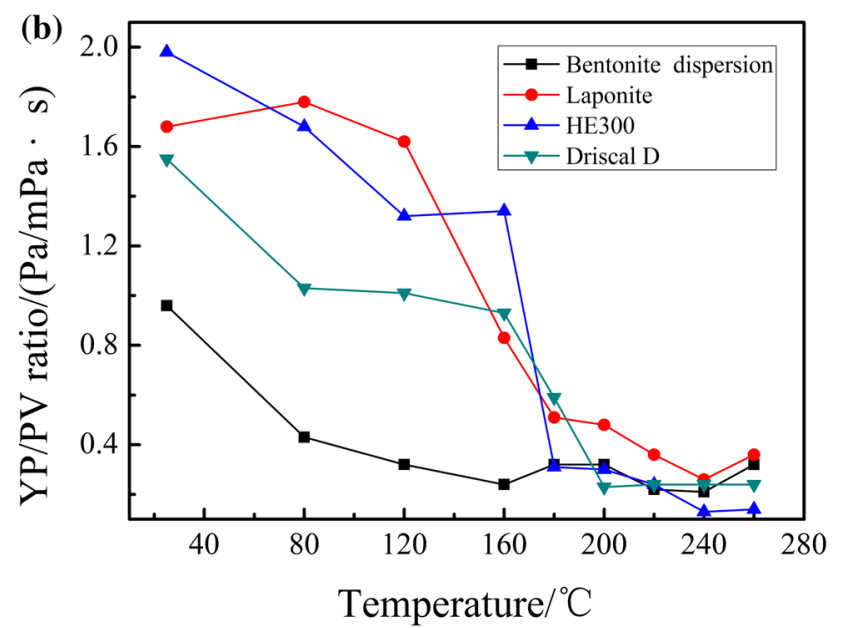

Fig. 6 Comparison of the performance between different high-temperature viscosifiers: a AV; $\mathbf{b}$ YP/PV ratio 


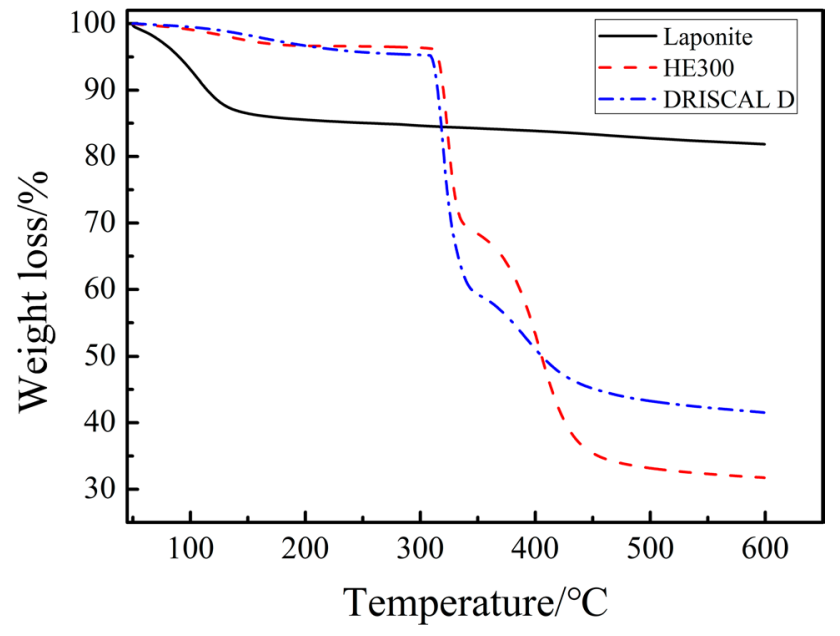

Fig. 7 TGA patterns of different high-temperature viscosifiers

$D$ begin to lose weight obviously for about $5 \%$ close to $300{ }^{\circ} \mathrm{C}$. The thermal degradation of polymer backbone of HE300 and DRISCAL D occurs at approximately $400{ }^{\circ} \mathrm{C}$, and the weight loss is about $50 \%$. However, the thermal decomposition process of laponite can be divided into two stages, and laponite loses weight slowly with increasing temperature. For example, the weight loss of laponite before $113^{\circ} \mathrm{C}$ is caused by volatilization of interlaminar free water, and its weight loss is $9.7 \%$. The results demonstrate that laponite has excellent thermal stability.

\subsection{Performance comparison of water-based drilling fluids with viscosifier at ultra-high temperature}

A water-based drilling fluid formulated with different hightemperature viscosifiers was prepared to investigate the compatibility of laponite with other drilling fluids additives and compare the performance of drilling fluids, and the results are listed in Table 3.
Table 3 reveals that AV value of formulation containing polymer viscosifier decreases after aging at $260^{\circ} \mathrm{C}$ for $16 \mathrm{~h}$, and FL value of formulation with different viscosifiers increases. In detail, AV value of formulations containing HE300 and DRISCAL D dramatically declines with respective reduction rates of $87.0 \%$ and $88.2 \%$, while AV value of formulation containing laponite raises with respective increasing rate of $25.2 \%$. These data further confirm the advantages of laponite over HE300 and DRISCAL D polymers in improving viscosifying properties of water-based drilling fluids under ultra-high temperature. Furthermore, laponite reveals good compatibility with other additives.

\section{Conclusions}

Laponite has excellent viscosifying ability and thermal stability, and the resistance to temperature is up to $260{ }^{\circ} \mathrm{C}$. For instance, the $4 \mathrm{wt} \%$ bentonite dispersion formulated with $1 \mathrm{wt} \%$ laponite has the same AV value of $16.5 \mathrm{mPa} s$ before and after aging at $260^{\circ} \mathrm{C}$ for $16 \mathrm{~h}$. The apparent viscosity reduction rate value of $4 \mathrm{wt} \%$ bentonite dispersion containing $1 \mathrm{wt} \%$ laponite is only $21.2 \%$ with the $220^{\circ} \mathrm{C}$ thermal aging time extending from 16 to $72 \mathrm{~h}$. Furthermore, the viscosification property of laponite is much better than the representative of high-temperature viscosifiers under ultra-high temperature. Overall, these findings demonstrate that laponite can be used as an ultra-high-temperature viscosifier and is applied in formulating ultra-high-temperature waterbased drilling fluid.
Table 3 Test results of ultrahigh-temperature water-based drilling fluids

\begin{tabular}{llclll}
\hline Formulation & $\begin{array}{l}\text { Thermal aging } \\
\left(260^{\circ} \mathrm{C} / 16 \mathrm{~h}\right)\end{array}$ & AV (mPa s) & $\begin{array}{l}\text { YP/PV ratio } \\
(\mathrm{Pa} / \mathrm{mPa})\end{array}$ & $\begin{array}{l}\text { FL }(\mathrm{mL}) \\
\begin{array}{l}\text { HTHP } \\
\text { filtrate } \\
(\mathrm{mL})\end{array}\end{array}$ \\
\hline Formulation A+1\% HE300 & Before & 103.5 & 0.52 & 4.0 & - \\
& After & 13.5 & 1.20 & 30 & 64 \\
Formulation A+1\% DRISCAL D & Before & 76.5 & 0.67 & 4.4 & - \\
& After & 9 & 0.48 & 38 & 72 \\
Formulation A+ 1\% laponite & Before & 55.5 & 0.82 & 3.6 & - \\
& After & 69.5 & 2.07 & 16.4 & 43 \\
Formulation A & Before & 16.5 & 0.17 & 3.6 & - \\
& After & 7.5 & 0.24 & 21 & 70 \\
\hline
\end{tabular}

${ }^{a}$ Formulation A: $3 w t \%$ sodium bentonite $+4 w t \%$ sulfonated lignite $(S M C)+4 w t \%$ lignite resin (SPNH) $+4 w t \%$ asphalt powder $+2 w t \%$ calcium carbonate powder $+1 w t \%$ sodium sulfite 
Acknowledgements This work was jointly supported by the National Natural Science Foundation of China (No. 41502345) and Research Foundation of Key Laboratory of Deep Geodrilling Technology, Ministry of Land and Resources (No. KF201810).

\section{Compliance with ethical standards}

Conflict of interest The authors declare that they have no conflict of interest.

\section{References}

1. Yan LL, Wang CB, Xu B, Sun JS, Yue W, Yang ZX (2013) Preparation of a novel amphiphilic comb-like terpolymer as viscosifying additive in low-solid drilling fluid. Mater Lett 105:232-235

2. Yan LL, Sun JS, Wang JH, Xu B, Xu XG, Wang CB (2014) Novel amphiphilic comb-like polymers: synthesis, characterization, and their properties as viscosifying and filtration additives for drilling fluids. J Macromol Sci Phys 53(6):1011-1026

3. Xie BQ, Liu XD, Wang HQ, Zheng LH (2016) Synthesis and application of sodium 2-acrylamido-2-methylpropane sulphonate/ $N$ vinylcaprolactam/divinyl benzene as a high-performance viscosifier in water-based drilling fluid. J Appl Polym Sci 133(43):1-12

4. Boul PJ, Abdulquddos S, Thaemlitz CJ (2017) High performance brine viscosifiers for high temperatures/SPE middle east oil and gas show and conference. Society of Petroleum Engineers

5. Morvan M, Espinat D, Lambard J, Zemb T (1994) Ultrasmall-and small-angle $X$-ray scattering of smectite clay suspensions. Colloids Surf A 82(2):193-203

6. Kroon M, Vos WL, Wegdam GH (1998) Structure and formation of a gel of colloidal disks. Int JThermophys 19(3):887-894

7. Au PI, Hassan S, Liu J, Leong YK (2015) Behaviour of LAPONITE ${ }^{\circ}$ gels: rheology, ageing, $\mathrm{pH}$ effect and phase state in the presence of dispersant. Chem Eng Res Design 101:65-73

8. Carrado KA, Thiyagarajan P, Winans RE, Botto RE (1991) Hydrothermal crystallization of porphyrin-containing layer silicates. Inorg Chem 30(4):794-799

9. Vicente I, Salagre P, Cesteros Y, Guirado F, Medina F, Sueiras JE (2009) Fast microwave synthesis of hectorite. Appl Clay Sci 43:103-107
10. Morgen TO, Krumova M, Luttikhedde H, Mecking S (2018) Freeradical dispersion polymerization of ethylene with laponite to polyethylene-clay nanocomposite particles. Macromolecules 51(11):4118-4128

11. Wang BX, Zhou M, Rozynek Z, Fossum JO (2009) Electrorheological properties of organically modified nanolayered laponite: influence of intercalation, adsorption and wettability. J Mater Chem 19(13):1816-1828

12. Brunier B, Sheibat-Othman N, Chniguir M, Chevalier Y, BourgeatLami E (2016) Investigation of four different laponite clays as stabilizers in pickering emulsion polymerization. Langmuir 32(24):6046-6057

13. Shahin A, Joshi YM (2010) Irreversible aging dynamics and generic phase behavior of aqueous suspensions of laponite. Langmuir 26(6):4219-4225

14. Au PI, Leong YK (2015) Surface chemistry and rheology of Laponite dispersions - zeta potential, yield stress, ageing, fractal dimension and pyrophosphate. Appl Clay Sci 107:36-45

15. Mohanty RP, Joshi YM (2016) Chemical stability phase diagram of aqueous Laponite dispersions. Appl Clay Sci 119:243-248

16. Liu F, Jiang GC, Wang K, Wang JX (2017) Laponite nanoparticle as a multi-functional additive in water-based drilling fluids. J Mater Sci 52(20):12266-12278

17. Qin Y, Ma KD, Jiang GC (2016) Synthesis and Study on Hectorite Viscosifier used in water base drilling fluid. Drill Fluid Complet Fluid 33(3):20-24

18. Huang XB, Shen HK, Sun JS, Lv KH, Liu JP, Dong XD, Luo SJ (2018) Nanoscale laponite as a potential shale inhibitor in water-based drilling fluid for stabilization of wellbore stability and mechanism study. ACS Appl Mater Interfaces 10(39):33252-33259

19. Xiong ZQ, Li XD, Fu F, Li YN (2019) Performance evaluation of laponite as a mud-making material for drilling fluids. Pet Sci. https://doi.org/10.1007/s12182-018-0298-y

20. Practice Recommended (2009) Recommended practice for field testing of water-based drilling fluids, 4th edn. API Publishing Services, Washington

Publisher's Note Springer Nature remains neutral with regard to jurisdictional claims in published maps and institutional affiliations. 